\title{
Optimization of different welding processes using statistical and numerical approaches- A reference guide
}

\author{
K. Y. Benyounis ${ }^{* 1}$ and A. G. Olabi*2 \\ 1- Dept of Industrial Eng., Garyounis University, Benghazi, Libya, P. O. Box 1308 \\ 2- School of Mechanical and Manufacturing Eng. Dublin City University, Dublin, Ireland. \\ khaled.benyounis2@mail.dcu.ie and abdul.olabi@dcu.ie
}

\begin{abstract}
Welding input parameters play a very significant role in determining the quality of a weld joint. The joint quality can be defined in terms of properties such as weld-bead geometry, mechanical properties, and distortion. Generally, all welding processes are used with the aim of obtaining a welded joint with the desired weld-bead parameters, excellent mechanical properties with minimum distortion.

Nowadays, application of Design of Experiment (DoE), Evolutionary algorithms and computational network are widely used to develop a mathematical relationship between the welding process input parameters and the output variables of the weld joint in order to determine the welding input parameters that lead to the desired weld quality. A comprehensive literature review of the application of these methods in the area of welding has been introduced herein. This review was classified according to the output features of the weld, i.e. bead geometry and mechanical properties of the welds.
\end{abstract}

Keywords: Quality of weld, welding, RSM, Ann, Taguchi, optimization.

\section{Introduction}

Generally, the quality of a weld joint is directly influenced by the welding input parameters during the welding process; therefore, welding can be considered as a multi-input multi-output process. Unfortunately, a common problem that has faced the manufacturer is the control of the process input parameters to obtain a good welded joint with the required bead geometry and weld quality with minimal detrimental residual stresses and distortion. Traditionally, it has been necessary to determine the weld input parameters for every new welded product to obtain a

\footnotetext{
* Corresponding authors: K. Y. Benyounis and A. G. Olabi, Tel. +353 1700 7718, Fax: +353 1700 5345. E-mails: khaled.benyounis2@mail.dcu.ie, abdul.olabi@dcu.ie
} 
welded joint with the required specifications. To do so, requires a time-consuming trial and error development effort, with weld input parameters chosen by the skill of the engineer or machine operator. Then welds are examined to determine whether they meet the specification or not. Finally the weld parameters can be chosen to produce a welded joint that closely meets the joint requirements. Also, what is not achieved or often considered is an optimised welding parameters combination, since welds can often be produced with very different parameters. In other words, there is often a more ideal welding parameters combination, which can be used if it can only determined.

In order to overcome this problem, various optimization methods can be applied to define the desired output variables through developing mathematical models to specify the relationship between the input parameters and output variables. In the last two decades, Design of Experiment (DoE) techniques have been used to carry out such optimization. Evolutionary algorithms and computational network have also grown rapidly and been adapted for many applications in different areas.

In this paper a comprehensive literature review of the application of these techniques is presented. This review shows the correlation between the input parameters and the output variables, the paper also presents the optimization of the different welding processes through the mathematical models. The classification of this literature review will be according to the weld joint features.

\section{2-Weld-bead geometry}

Theoretically, an extremely thin fused layer might be sufficient for connecting the parts to be joined. The fusion layer should also not be thicker than necessary in order to avoid wasting of energy, edge burn-off, sagging of the weld pool and deep weld end craters [1]. Control of weld bead shape is essential as the mechanical properties of welds are affected by the weld bead shape [2]. Therefore, it is clear that precise selection of the process parameters is necessary.

\subsection{Factorial Design}

Raveendra and Parmar [3] have built mathematical models using the fractional factorial technique to predict the weld bead geometry and shape relations (penetration, width, reinforcement height, width to penetration ratio and percentage dilution). The base metal was a 
13-mm thick low carbon structural steel plate. The parameters of the FCAW process considered in this work were: arc voltage, welding current, welding speed, gun angle and nozzle-to-plate distance. They have developed models which can be used either to predict the bead geometry or to determine a combination or a range of parameters to obtain the desired bead geometry dimensions within the factors domain. Furthermore, these models can also be used in a production system for automatic control of welding conditions.

Gupta and Parmar [4] have used the fractional factorial technique $2^{5-1}$ to develop mathematical models to predict the weld bead geometry and shape relationships for the SAW of microalloyed steel; the thickness ranged between 10 and $16 \mathrm{~mm}$. They investigated bead penetration, weld width, reinforcement; dilution, width/penetration, and width/reinforcement as affected by wire feed rate, open circuit voltage, nozzle-to-plate distance, welding speed and workpiece thickness. It was found that the fractional factorial technique was convenient for the prediction of the main effects and the interaction effects of different combinations of welding parameters. Mathematical models were developed which can be used effectively to predict the weld zone dimensions. Moreover, they mentioned that, if a specific set of requirements for weld bead dimensions is given, these models can be used in a computer program to determine a combination of parameters which will meet the requirements.

The development of the mathematical models using the five level factorial technique to predict the weld bead geometry for depositing 316L stainless steel onto structural steel IS 2062 in single wire surfacing using the SAW process was studied by Murugan et al. [5]. They investigated the following weld bead parameters (penetration, reinforcement, width and dilution) as affected by the following SAW process variables (open-circuit voltage, wire feed-rate, welding speed and nozzle-to-plate distance). It was shown that the developed models can be employed easily in automated or robotic welding, in the form of a program, for obtaining the desired high quality welds. The results demonstrated that the bead penetration is not affected significantly by the voltage and nozzle-to-plate distance and the width is not affected by the latter. Furthermore, it was proven that the dilution increased when voltage and welding speed are increased from its lowest level to its centre level, but dilution is not affected by changes in voltage when welding speed is at its centre level. They found that the dilution decreased with increasing voltage when welding speed is increased from its centre level to its highest level. 
Murugan and Parmar [6] used a four-factors 5-levels factorial technique to predict the weld bead geometry (penetration, reinforcement, width and dilution \%) in the deposition of $316 \mathrm{~L}$ stainless steel onto structural steel IS2062 using the MIG welding process. The following process parameters were controlled; open-circuit voltage, feed rate, welding speed and nozzle-to-plate distance. It was demonstrated that this factorial technique can be employed easily for developing mathematical models to predict the weld bead geometry within the factors ranges and these models can be fed into automatic robotic surfacing in a form of program to obtain the desired high quality. In addition to this, the effect of each factors on the weld features were determined and presented graphically.

\subsection{Linear regression}

Yang et al. [7] have used linear regression equations for computing the weld features (melting rates, total fusion area, penetration, deposit area, bead height and bead width) from SAW process variables (electrode extensions range, welding voltage, welding current, welding speed and electrode diameter) using both positive and negative electrode polarity. The base material was a $19 \mathrm{~mm}$ thick ASTM A36 steel plate. They managed to develop regression equations for each weld feature in both polarity conditions. Their results indicated that the linear regression equations were equally useful for computing the various features of the SAW process.

The effect of process parameters (welding current, travel speed, gap width, bead height and arc deflection current) on the bead shape in a narrow gap-GTAW process with magnetic arc oscillation was studied by Starling et al [8]. Two AISI 304L stainless steel plates $(9.5$ and $6 \mathrm{~mm}$ thick) were employed to prepare the narrow gap joints and an AWS ER308L wire of $0.96 \mathrm{~mm}$ diameter was used as a filler metal. Statistical experimental design and linear-regression modelling were used in this investigation to develop the model. It was shown that the arc oscillation has little effect on the lateral fusion of the joint, however, this oscillation does improve bead shape by increasing its concavity. It was reported that when the gap width was reduced, the undercutting level tended to increase remarkably. Also, the effects of other welding parameters were in good agreement with the results of previous works.

Kim et al. [9] have studied the interrelationship between robotic $\mathrm{CO}_{2}$ arc welding parameters and bead penetration by developing mathematical models using factorial techniques to predict the desired bead penetration. Partial-penetration and single-pass welds were fabricated 
in $12 \mathrm{~mm} \mathrm{SS400} \mathrm{plates} \mathrm{based} \mathrm{on} \mathrm{controlling} \mathrm{four} \mathrm{different} \mathrm{process} \mathrm{parameters} \mathrm{(arc} \mathrm{voltage,}$ welding current, welding speed and welding angle). They found that all the investigated parameters affect the bead penetration. They suggested extending the empirical formulae to plates of varying thickness and many other parameters which were not included in their research.

Kim et al. [10] have employed factorial design to correlate the robotic GMAW process parameters (welding voltage, welding speed and arc current) to three responses (bead width, bead height and penetration) for optimization purposes. The material used was plates of AS 1204 mild steel adopting the bead-on-plate technique. Electrode wire with a diameter of $1.2 \mathrm{~mm}$ with the same mechanical and physical properties of the base metal was used. Their results showed that all process parameters influenced the responses and the models developed are able to predict the responses with $0-25 \%$ accuracy.

\subsection{Response Surface Methodology}

Murugan and Parmar [11] developed mathematical models using response surface methodology (RSM) to study the direct and interaction effects of SAW parameters (open circuit voltage, wire feed rate, welding speed and nozzle-to-workpiece distance) on the cladding geometry (depth of penetration, height of reinforcement, weld width and dilution \%). The process parameters obtained from the developed models were employed to clad IS2062 structural steel plate of 20-mm thickness using 316L stainless steel wire of $3.15 \mathrm{~mm}$ diameter. They concluded that a low dilution of $22.57 \%$ can be produced by both high voltage and high welding speed or by low voltage and low welding speed. It was reported that the hardness of the existing martensitic structures at the intermediate mixed zones in overlays was below $400 \mathrm{VHN}$, due to low carbon content in the cladding.

Gunaraj and Murugan [12] have highlighted the use of RSM to develop mathematical models and plot contour graphs relating important input parameters namely the open-circuit voltage, wire feed rate, welding speed and nozzle-to-plate distance to some responses namely, the penetration, reinforcement, width and percentage dilution of the weld bead in SAW of pipes. They demonstrated that all responses decrease with increasing welding speed. Also, when the nozzle-to-plate distance increases all responses decrease, but reinforcement increases. Moreover, an increase in the wire feed rate results in an increase in all responses but the width remains unchanged. 
In 1999, Gunaraj and Murugan [13] also studied the effect of SAW parameters on the heat input and the area of HAZ for low carbon steel with two joint types, bead-on-plate and bead-onjoint, using mathematical models developed by RSM. They found that for the same heat input, the area of the HAZ is greater for the bead-on-plate than that for bead-on-joint. They found that the effect of SAW parameters on the area of HAZ in both cases follows the same trend.

Koleva [14] has developed models to investigate the influence of electron beam welding (EBW) parameters namely electro beam power, welding velocity, distance from the main surface of the magnetic lens to the focus point and the distance between the magnetic lens and the sample surface on the welding depth and width. The experiment was performed with samples of austenitic steel, type $1 \mathrm{H} 18 \mathrm{NT}$. Also, the desirability approach was used to find the optimal welding conditions which would lead to the desired depth and width. The author has suggested the use of the developed models for on-line control of the process. This allows the selection of the optimal levels, eliminates the time required for testing and prevent losses of components.

Gunaraj and Murugan have divided their study into two parts, in the first part [15] they developed a model to relate the weld bead volume to SAW parameters with slightly changed open-circuit voltage limits from those used in their previous work [68]. This change is reflected in the development of new models to correlate the rest of the responses mentioned earlier to the process. Their results revealed that the penetration reduces, and the bead width and dilution increase considerably as welding voltage increases. Also, they proved that the reinforcement is least when all SAW parameters are at their upper limits and the wire feed rate is at its lower limit. In the second part [16] the total volume of the weld bead was optimized (minimized) by keeping the other bead parameters as constrains to obtain sound welded pipes. Also, sensitivity analysis was carried out to predict the effect of the other bead parameters on the total volume.

Gunaraj and Murugan [17] continued their previous study and successfully investigated the effect of SAW parameters on HAZ characteristics. They pointed out that the heat input and wire-feed rate has a positive effect, but welding speed has a negative effect on all HAZ characteristics. They also concluded that the width of HAZ is of a maximum (about $2.2 \mathrm{~mm}$ ) when the wire-feed rate and the welding speed are at their minimum limits.

The effect of the laser welding parameters on the bead geometry of $2.5 \mathrm{~mm}$ thick AISI304 stainless steel has been investigated by Manonmani et al. [18]. In this study the relationship between the process parameters (beam power, welding speed and beam incidence angle) and the 
weld bead parameters (penetration, bead width and area of penetration) has been developed using RSM. To verify the developed models a conformity test run were carried out using intermediate values of the process parameters. It was confirmed that the model developed were accurate since the error percentages were between $-4.317 \%$ and $3.914 \%$. It was demonstrated that the depth of penetration and penetration area increase as the beam power and the beam angle increase. Also, as the welding speed increases, the width decreases, whereas the penetration depth and area increase to an optimum value and then decrease with further increases in welding speed. This is due to the fact that the effect of keyholing is predominant at lower speed and as the welding speed is increased the mode of heat transfer changes from keyholing to conduction type of welding. It was reported that the variation in the bead width is slightly affected by the process parameters.

In 2005, Gunaraj and Murugan [19] extended their study and managed to establish mathematical expressions to predict the penetration size ratio 'PSR' (the ratio of bead width to the height of penetration) and the reinforcement form factor 'RFF' (the ratio of bead width to the height of reinforcement). These expressions and the others developed earlier can be fed into a computer, relating the weld bead dimensions to the important SAW parameters, in order to optimize the process to obtain the required bead shape and weld quality.

Koleva [20] has carried out another work by applying RSM to establish the relationship between performance characteristics (weld depth, weld width and thermal efficiency) and its influencing factors (beam power, welding velocity, focus position, focusing current of the beam and the distance to the sample surface) for EBW of austenitic stainless steel. Optimal welding regimes were found through the thermal efficiency optimization. New statistical approaches were proposed to choose the focus position at a condition of maximum thermal efficiency and welding depth.

Benyounis et al. [21] have applied RSM to investigate the effect of laser welding parameters (laser power, welding speed and focal point position) based on four responses (heat input, penetration, bead width and width of $\mathrm{HAZ}$ ) in $\mathrm{CO}_{2}$ laser butt-welding of medium carbon steel plates of $5 \mathrm{~mm}$ thick. They found that the heat input plays an imported rule in the weld-bead parameters; welding speed has a negative effect while laser power has a positive effect on all the responses. Again Benyounis et al. [22] have used the previous models [21] to optimize the process. Two optimization criteria were considered; the desirability approach was used to find the 
optimal conditions in the numerical optimization. They reported that full penetration has a strong effect on the other bead parameters. Also, strong, efficient and low cost weld joint could be achieved using the optimal conditions.

Koleva and Vuchkov [23] have established the relationship between EBW parameters (beam power, welding velocity and focus position) and weld-depth and weld-width using RSM in order to improve the quality of the process in mass production. They reported that the optimal process parameters values when welding stainless steel are: power $6.5-8 \mathrm{~kW}$, welding velocity $11.667-1.333 \mathrm{~mm} / \mathrm{s}$ and focus position $78 \mathrm{~mm}$ below the sample surface.

Kannan and Murugan [24] have studied the effect of flux cored arc welding process parameters (welding current, welding speed, nozzle-to-plate distance and welding torch angle with reference to vertical) on the duplex stainless steel clad quality in terms of penetration, width, reinforcement and percentage dilution. It was demonstrated that the process parameters have a significant effect on the bead geometry of the clad. The effect of the input process parameters on the clad quality parameters have been presented in graphical form, which assist in finding the welding parameters combination that would lead to the desired clad quality quickly.

\subsection{Artificial Neural Networks (ANNs)}

Andersen et al. [25] have explained some concepts related to neural networks and how they can be used to model weld bead geometry, in terms of equipment parameters, in order to evaluate the accuracy of neural networks for weld modelling. They carried out a number of simulations and they used actual GTAW data for this purpose. The data consisted of values for voltage, current, electrode travel speed and wire feed speed and the corresponding bead width, penetration, reinforcement height and bead cross-sectional area. The performance of neural networks for weld modelling was presented and evaluated using actual welding data. It was concluded that the accuracy of neural networks modelling is fully comparable with the accuracy achieved by more traditional modelling schemes.

Evaluation of ANN for monitoring and control of the plasma arc welding process was carried out by Cook et al. [26]. Three areas of welding application were investigated in this work: weld process modelling, weld process control and weld bead profile analysis for quality control. A network was constructed to determine the torch standoff, forward current, reverse current and travel speed for desired crown width and root width. The base material was 2219 aluminium 
alloy in the form of plates $6.35 \mathrm{~mm}$ thick; the joint type was bead-on-plate. It was confirmed that ANNs are powerful tools for analysis, modelling and control of such applications. Also, the results obtained when analyzing weld profile data suggested that ANNs can yield real-time results of equal or better accuracy and reliability than previously used data analysis algorithms.

Vitek et al. [27] have developed a model to predict the weld pool shape parameters (penetration, width, width at half-penetration and cross-section area) in pulsed Nd-YAG laser welds of Al-alloy 5754 using neural network. They have considered the following process parameters; travel speed, average power, pulse energy and pulse duration. They developed a routine to convert the shape parameters into a predicted weld profile which was based on the actual experimental weld profile data. The accuracy of the model was excellent. They concluded that this approach allows for instantaneous results and therefore, offers advantages in applications where real-time predictions are needed and computationally intensive predictions are too slow.

A comparison between back-propagation and counter-propagation networks in the modelling of the TIG welding process was made by Juang et al [28]. The complicated relationships between the welding process parameters and the weld pool features were considered. The input process parameters were: welding speed, wire feed speed, cleaning percentage, arc gap and welding current, while the output features were: front height, front width, back height and back width. The base metal was pure 1100 aluminium with a plate thickness of $1.6 \mathrm{~mm}$. The experimental results, for the TIG welding process, showed that the counterpropagation network has a better learning ability than the back-propagation network. However, the back-propagation network has better generalization ability than the counter-propagation network.

Chan et al. [29] have proposed a model to predict the bead-on-plate weld geometry (bead width, height, penetration and bag length at $22.5^{\circ}$ ) in GMAW of low alloy steel with C25 shielding gas. The process parameters were: current, voltage, wire travel speed and workpiece thickness. Back propagation network (BPN) was used. Their results revealed that the weld bead geometry problem can be accurately modelled by using BPN. A new weld bead parameter $l_{22.5}$ (length from the origin to periphery at $22.5^{\circ}$ from the work piece surface) has been defined.

Jeng et al. [30] have used both BPN and learning vector quantization neural networks to predict the laser welding (LW) parameters for butt joints. The input parameters included were workpiece thickness and welding gap, while the output parameters 'responses' were optimal 
focus position, acceptable welding parameters of laser power, welding speed and weld quality, including weld width, undercut and distortion. They managed to integrate all the networks together to make an accurate prediction model of the laser welding parameters. Therefore, the limitation in the industrial application of LW for butt joints can be reduced through the use of this well established model.

Usage of ANN to model the GMAW process was reported by Nagesh and Datta [31]. BPN was used to associate the welding process parameters (electrode feed rate, arc power, arc voltage, arc current and arc length) with output features of bead geometry (bead height and width, penetration depth and area). The workpiece material was grey cast iron and a mild steel electrode was used. It was showed that there was a small error percentage difference between the estimated and experimental values, which indicates that the neural networks can yield fairly accurate results.

Ridiings et al. [32] have applied neural networks technique to predict the outer diameter of the weld bead shape for three wire, single pass per side, submerged arc, line-pipe seam welds using the following welding process parameters: current, voltage and angle for the three wires as well as the welding speed, stickout and spacing of wires. The plates welded were of various thicknesses from 15.9 to $25.4 \mathrm{~mm}$ and they were varied in strength from X52 to X65. The welding was carried out using alloyed wires with a $4 \mathrm{~mm}$ diameter. It was shown that the applied technique can predict a weld bead shape with a high degree of confidence. The contribution of each factor to the variation in the final weld bead shape was determined. Furthermore, it was mentioned that an efficient model can be built using different neural networks to predict the bead shape when using a smaller number of measurements for separate areas. However, the higher the number of measurements the better the accuracy of the technique.

Christensen et al. [33] have developed a multilayer feed forward network for modelling and online adjustment of GMAW process parameters to guarantee a certain degree of quality. In this study, butt joint welding with full penetration of standard steel S135 with $3 \mathrm{~mm}$ thickness was carried out. The process parameters were; wire feed speed, voltage, welding speed and gap width while the network inputs were back bead width and back bead height. In open loop control strategy, it has been demonstrated that use of the model to provide high quality welding is feasible and the network training was straightforward and effective. Whereas, in the closed loop 
experiments a single input and single output control scheme was investigated, it was shown that it was applicable for adaptive control of GMAW with some limitations.

\subsection{Taguchi Method}

Juang and Tarng [34] have adopted a modified Taguchi method to analyze the effect of each welding process parameter (arc gap, flow rate, welding current and speed) on the weld pool geometry (front and back height, front and back width) and then to determine the TIG welding process parameters combination associated with the optimal weld pool geometry. It was experimentally reported that, the four smaller-the-better quality characteristics, 'four responses' of the weld pool in the TIG welding of S304 stainless steel of $1.5 \mathrm{~mm}$ in thickness are greatly improved by using this approach.

Lee et al. [35] have used the Taguchi method and regression analysis in order to optimize Nd-YAG laser welding parameters (nozzle type, rotating speed, title angle, focal position, pumping voltage, pulse frequency and pulse width) to seal an iodine-125 radioisotope seed into a titanium capsule. The accurate control of the melted length of the tube end was the most important to obtain a sound sealed state. It was demonstrated that the laser pulse width and focal position were the laser welding parameters that had the greatest effects on the $\mathrm{S} / \mathrm{N}$ ratios of the melted length. The optimal welding conditions were obtained at a pulse width of $0.86 \mathrm{~ms}$ and a focal position of 3.18 to $3.35 \mathrm{~mm}$. Furthermore, confirmation experiments were conducted at the optimal welding conditions, it can be said that the titanium tube ends were sealed perfectly.

\subsection{Combination of two Techniques}

A comparison of back-bead prediction (width and depth) of the GMAW process using multiple regression analysis (MRA) and ANN analysis have been carried out by Lee and Um [36]. The controlled process parameters were: Gap, current, voltage and speed. The workpiece material was SS41 mild steel. It was found that the error rate predicted by the ANN was smaller than that predicted by MRA, in terms of the width and depth of the back-bead. It was also found that between the two predictions, the prediction of the width was superior to the prediction of the depth in both methods. Moreover it was concluded that the welding speed was the most important factor in the geometry of the back-bead, followed by welding current, gap and arc voltage. 
Park and Rhee [37] have analyzed the signal of the plasma, or spatter, and bead size, to develop a bead size estimation system using the regression method and a neural networks method. It was found that the relationship is a nonlinear function caused by the penetration state. In contrast, the authors concluded that the regression models were appropriate for estimation when classifying the penetration state as partial penetration and full penetration, whereas, the neural network was a very accurate estimation approach for bead size.

Kim et al. [38] have presented an intelligent algorithm to establish the relationship between GMA $\mathrm{CO}_{2}$ welding process parameters; (number of passes, arc current, welding voltage and welding speed and bead height), in order to predict the bead height using a neural network and MRA for the robotic multi pass butt welding process of BV-AH32 steel with $12 \mathrm{~mm}$ in thickness. Their results showed that all the process parameters would influence the bead height. Also, the developed models were able to determine the welding condition required to achieve the desired bead height, which helped to develop an automatic control system and to establish guidelines and criteria for the most effective joint design.

The effect of energy input per unit length of weld from the travelling heat source on the laser efficiency and weld quality have been investigated by Casalino et al. [39]. A number of austenitic stainless steel butt joints were produced by $\mathrm{CO}_{2}$ laser welding irradiation. The welding efficiency was calculated as the melted area to energy input per unit length ratio. Moreover, the weld crown and depth were measured in order to evaluate the quality of the joint. ANN was used to correlate the collected data to the process parameters (laser power, speed and material thickness), and then these parameters were clustered using a fuzzy C-means algorithm. In order to select the optimum network parameters a 24-factorial design was used. Finally, a model was built to choose the most suitable laser welding process for producing high efficiency and superior quality. It was recommended to consider more input factors such as laser focus, different materials and different weld beads.

Kim et al. [40] have used genetic algorithm (GA) and RSM to determine the optimal welding conditions in GMAW process, the base metal was mild steel with a thickness of $5.8 \mathrm{~mm}$. First, the near-optimal conditions were determined through a GA, and then the optimal conditions were determined over a relatively small region by using RSM. The desirability function approach was used to find the optimal conditions. They correlated the following parameters; wire-feed rate, welding voltage and welding speed to some responses, namely, bead width, penetration and 
height. They concluded that by combining these two techniques, a good result for finding the optimal welding conditions can be obtained.

A comparison between GA and RSM in the optimization of the GMAW process when welding of $9.5 \mathrm{~mm}$ thick mild steel with a square-groove butt joint was carried out by Correia et al. [41]. The criterion was to choose the best values of three parameters (reference voltage, wire feed rate and welding speed) based on four quality responses (deposition efficiency, bead width, depth of penetration and reinforcement). Their results indicated that both methods are capable of finding the optimum conditions. Also, they found that GA is a powerful tool for optimization, especially in irregular experimental regions, because there is no need to generate models. A selection of the correct settings of the GA tool parameters, such as, population number, number of generations, etc. was required. On the other hand, the RSM technique found a better compromise between the evaluated responses than the GA, but RSM is not able to build a model to fit the data over irregular experimental regions.

\subsection{Other Techniques}

D. Kim et al. [42] have proposed a method for determining the near-optimal setting of GMAW process parameters (wire feed rate, welding voltage and welding speed) in welding plates made of mild steel with a thickness of $0.4 \mathrm{~mm}$ using a controlled random search (CRS). The CRS was used to determine the welding process parameters by which the desired weld bead (front bead height, back bead width and penetration) can be formed. They managed to determine the optimal welding conditions that lead to the desired weld beads.

Tarng et al. [43] have constructed the relationship between TIG welding process parameters (gap, gas flow rate, current, welding speed and cleaning) and weld bead geometry parameters (front depth, back height, back width and cluster number). To search for the process parameters with the optimal weld pool geometry, an optimization algorithm called simulated annealing (SA) was applied to the network. Finally, the quality of the aluminium welds based on the output variables was classified and verified by a fuzzy clustering technique. The membership gradings corresponding to categories, good, fair and poor, were listed, and the results showed that the membership gradings for the category 'good' was much higher. Therefore, good weld quality can be obtained by using the optimal welding process parameters. 


\section{3- Mechanical properties}

In any welding process, the input parameters have an influence on the joint mechanical properties. By varying the input process parameters combination the output would be different welded joints with significant variation in their mechanical properties. Accordingly, welding is usually done with the aim of getting a welded joint with excellent mechanical properties. To determine these welding combinations that would lead to excellent mechanical properties. Different methods and approaches have been used to achieve this aim. The following is a review of some articles that utilized these techniques for the purpose of optimizing the welding process in order to achieve the desired mechanical properties of the welded joint.

\subsection{Factorial Design}

Application of the factorial technique for weld quality prediction for the plasma transferred arc (PTA) weld cladding process on mild steel was investigated by Harris and Smith [44]. The process variables considered were current, powder feed rate, torch travel speed, oscillation width and torch stand-off distance. Four deposit quality features were measured, namely; deposit height, width, hardness and dilution. It was confirmed that all the process variables were acting as main process parameters in controlling the deposit quality. Also, it was reported that the PTA process is an excellent choice for depositing high quality hard-facing deposits at low controlled dilution.

Optimization of friction welding of dissimilar materials using factorial design was studied by Murti and Sundaresan [45]. They studied the friction welding of three industrially useful dissimilar materials: low alloy steel to austenitic stainless steel; medium carbon steel to high speed steel and aluminium to stainless steel. The main aim was to determine the metallurgical and mechanical behaviour of the friction welded joints produced using optimum welding conditions. Three mathematical models were developed to relate the notched tensile strength (NTS) and shear energy to the process parameters, namely: friction pressure, friction time and forging pressure with different levels according to the two materials which formed the joint. It was reported that the statistical experimental design was useful for reducing the number of trials necessary to optimize the welding conditions for friction welding. Also, the strength of the joint which was produced by using the optimized condition was in fair agreement with the predicted 
results. Moreover, in all cases, the joint strength was at least as high as those of the softer of the two materials that formed the joint.

Control of distortion in robotic $\mathrm{CO}_{2}$-shielded FCAW was investigated by Arya and Parmar [46]. A three level fractional factorial technique was used to develop mathematical models to predict the angular distortion in $10 \mathrm{~mm}$ thick low carbon steel. The effect of arc voltage, wire feed rate, welding speed and groove angle on the angular distortion in single vee butt welds was investigated with and without sealing run. It was concluded that the models developed were fairly accurate and can be usefully employed for controlling the angular distortion in automated welding lines using the FCAW process.

Zhou et al. [47] have utilized factorial experimentation to investigate the influence of joining parameters (rotational speed, frictional time and pressure) on the NTS of dissimilar aluminiumbased metal matrix composite MMC/AISI304 stainless steel friction joints. It was observed that frictional pressure and rotational speed have a statistically-significant effect on the NTS values. Moreover, they reported that the highest NTS occurs in joints produced at a high frictional pressure of $120 \mathrm{MPa}$.

Fatigue endurance of flux cored arc welded (FCAW) cruciform joints containing lack of penetration using design of experiment was studied by Balasubramanian and Guha [48]. The aim was to optimise some dimensional factors that affected the fatigue life of cruciform joints made of quenched and tempered steel (ASTM $517 \mathrm{~F}$ grade). It was mentioned that the techniques described in this work were fairly simple and economical to optimise the time consuming fatigue tests. It was also reported that some factors affecting the fatigue endurance were optimised to attain a maximum fatigue life, but the validity of the procedure is limited to the factors domain considered for the investigation. It was noted that the ANOVA technique is the most convenient to identify the significance of the main effects and interaction effects of joint dimensions. The same authors [49] continued their investigation by developing mathematical models using design of experiment to predict the fatigue life of shielded metal arc welding SMAW and FCAW cruciform joints failing from root and toe regions. Using the developed models the fatigue life of SMAW and FCAW cruciform joint can be predicted at a 95\% confidence level, however, the validity of the models is limited to the factors domain. It was found that the factorial experimentation technique design of experiment is more economical for predicting the effect of various factors on fatigue life through conducting a minimum number of experiments. 
Koganti et al. [50] have employed a full factorial design to define the optimum weld MIG process parameters for non-treatable 5754 aluminium alloys. The effects of weld process parameters on the lap joint failure load (tensile-shear strength) and weld penetration were investigated. The process parameters were: power input (torch speed, voltage, current, wire feed rate), pulse frequency and gas flow rate. The joint strengths and weld penetration were measured for various operating ranges of weld factors. It was indicated that the power input and the gas flow rate were the two significant factors based on lap shear load to failure and weld penetration data. It was reported also, that the lower the power input, the lower the shear load to failure and depth of penetration and vice versa. The optimum factor settings for higher joint strength were high power input and high gas flow rate.

Sampath [51] has presented an innovative constrains-based approach that proved quite efficient in developing a specification for consumable solid-wire electrodes for GMAW of HSLA-80 and HSLA-100 steels that meet or exceed the US Navy requirements. Initially, he converted the US Navy requirements into a set of constraints which related the chemical composition of steels to certain metallurgical characteristics. Subsequently, a $2^{3}$ factorial design was used to develop a batch of welding electrodes in order to evaluate their performance. Among the eight electrodes used, it was shown that two electrodes met or exceeded ER-100s requirements, while one electrode met or exceeded ER-120s requirements. It was concluded that the use of this approach greatly reduced the risk inherent in developing electrode specifications.

Pine et al. [52] have presented an experimental and numerical study to determine the torsional stiffness, elastic limit and ultimate strength of spot welded, adhesively bonded and weld-bonded box sections. They investigated a variety of factors, namely: joining technique, sheet thickness, steel strength, section area, section design and end weld using factorial design techniques to determine their effects on the torsional properties of box sections. The authors have concluded that the joining technique, section area and section thickness were the main factors which have the greatest effect on the torsional stiffness of the box sections. It was found that the torsional stiffness can be improved without substantial weight gain by changing the joining technique from $50 \mathrm{~mm}$ pitch spot welds to adhesive bonding, increasing the section area and to a lesser extent, changing the section design. Furthermore, the steel strength was the most important factor in determining the elastic limit and ultimate strength. 


\subsection{Response Surface Methodology}

Wang and Rasmussen [53] have investigated the inertia welding process of low carbon steels using RSM, with the purpose of establishing an empirical functional relationship between the process parameters (the axial pressure, the initial rubbing velocity and the total moment of inertia) and the breaking strength of the joint. It was concluded that a relatively wide range of operating conditions would produce successful welds. Also, they observed that the average microhardness at the weld was about 27 percent higher than the base material and the ideal weld should be made with the least possible amount of kinetic energy as long as full penetration at the interface is achieved.

Yamaguchi et al. [54] have investigated the friction welding process of 5056 aluminium alloy using RSM. Their aim was to find the optimal welding conditions that would yield maximum tensile strength at the weld. The process input parameters were friction pressure, up-set pressure, friction time, rotating speed and braking time. It was reported that the successful welds showed $89.2 \%$ joint efficiency in tensile strength. It was also observed that the friction layer formed at the friction interface disappeared in these successful weld runs.

Koichi et al. [55] have studied the combination of welding conditions that produce maximum notched tensile strength of friction welded joints of S4 5C carbon steel using RSM. They managed to correlate the process parameters (friction pressure, upset pressure, friction time, rotation speed and braking time) to the tensile strength of the weld joint. Successful weld strength was obtained using the optimal welding condition predicted by the empirical equation.

Benyounis et al. [56] have proposed models using RSM to investigate the effect of welding parameters in SAW (welding current, arc voltage and welding speed) on the impact strength at two testing temperatures of $50{ }^{\circ} \mathrm{C}$ and $27{ }^{\circ} \mathrm{C}$. The aim was to predict and optimise the impact strength of the spiral-welded joints with respect to the process parameters. It was observed that the welding current was the most significant factor associated with the impact strength, then the welding speed, whereas the welding voltage has no significant effect within the factors domain investigated. They listed the optimal welding conditions that would lead to acceptable impact strength with improving the process productivity.

The production of strong and stiff, aluminium-titanium, multi-layered composites (laminates) by explosive welding was undertaken by Ege et al. [57]. The study was performed using RSM to investigate the mechanical behaviour of the laminates with changes in two 
characteristic variables; abundance of interfaces and volume percentage of the more ductile component. Eighteen laminates were produced and then one-step welding of these laminates was carried out by explosive-introduced pressuring. Yield strength, ultimate tensile strength and elongation were the responses under consideration. A second-order model was fitted to define the relationship between the yield strength and the two variables. It was reported that the mechanical properties of the laminates depend strongly on the relative amounts of the components, but only weakly on the abundance of the interface within the selected operability region. It was also mentioned, that with the aid of the developed model it is possible to fabricate laminates that are tailored to strength, density and load specifications.

Allen et al. [58] have proposed a model based on central composite design with the alpha parameter set equal to 2, for robotic gas metal arc welding of sheet metal of 409-gauge, stainless steel. The six factors controlled in this study were: wire feed speed, weld travel speed, arc voltage, contact-tube-to-work distance, root opening and offset. The objective was to minimize the weld cycle time by maximizing welding speed, while maintaining predictable weld quality over a range of worst-case processing conditions. The optimal welding conditions for this type of material with a lap joint were reported and confirmed by experimental tests. The effect of the process parameters was presented graphically.

Raghukandan [59] has conducted experiments to clad low carbon steel and copper plates using nitroglycerine explosive $(2500 \mathrm{~m} / \mathrm{s}$ detonation velocity). The aim was to adopt RSM to relate the bond and shear strength of the clad to four process factors (flyer thickness, loading ratio, angle of inclination and stand-off distance). Mathematical models were developed and the effect of process parameters on the responses was discussed. It was found that the flyer thickness, the loading ratio and the angle of inclination have significant contribution to the interfacial morphology of explosive clad.

V. Murugan and Gunaraj [60] have implemented RSM to correlate the angular distortion in GMAW of structural steel plate (IS: 2062) to the process parameters, namely: time gap between successive passes, number of passes and wire feed rate. The main and interaction effects of the process parameters were analyzed and presented. It was found that the number of passes had a strong effect on the response, therefore, to control the angular distortion in practice the number of passes has to be monitored carefully. Moreover, it was demonstrated that all the process parameters have a negative effect on the angular distortion. 
Benyounis et al. [61] have studied the effect of $\mathrm{CO}_{2}$ laser welding parameters (laser power, welding speed and focus position) on the impact strength and NTS of butt joints made of medium carbon steel plates. Two mathematical models were developed using RSM to describe the influence of the process parameters on the two responses. The main, quadratic and interaction effects of the process parameters on the two responses were determined quantitatively and presented graphically. It was reported that the welding speed is the main factor affecting the two responses; it was found that decreasing the welding speed from its highest level to lowest level would result in increasing both responses by $89.3 \%$ and $76.45 \%$ respectively. Laser power and focal point position have also strong effect on both responses investigated.

Benyounis et al. [62] have done another work to predict the residual stress for $\mathrm{CO}_{2}$ laser butt-welding joints of AISI304 stainless steel plates. The investigation is carried out using RSM to develop models in terms of the process input parameters mentioned earlier in [59] to predict the principal residual stress and its direction. It was observed that the travel speed and laser power were the main factors affecting the behaviour of the maximum residual stress. It was recommended to use the developed models to find the optimal welding conditions to obtain the welded joint with a minimum distortion.

Olabi et al. [63] have established the relationship between the $\mathrm{CO}_{2}$ laser welding parameters (laser power, welding speed and focus position) and the residual stress magnitude and distribution using RSM for butt joint welded components. The base material was AISI304 stainless steel plates with $3 \mathrm{~mm}$ thickness. Incremental hole drilling procedure with the standard seven increments was followed to measure the residual stress magnitude and distribution at three locations, on HAZ, $10 \mathrm{~mm}$ and $20 \mathrm{~mm}$ from weld centreline repetitively. Twenty one models were developed to describe the residual stress behaviour. A procedure of four steps was presented to use the developed models in order to predict the residual stress magnitude at the proposed welding conditions and at a given position. Also, the effect of the process parameters on residual stress behaviour has been determined quantitatively and presented graphically.

Benyounis et al. [64] have developed a mathematical model using RSM to relate the failure load to the laser welding parameters namely: laser power, welding speed and focal position. The effect of the process parameters on the failure load and the tensile-shear strength of the lap joint made of AISI304 with $1 \mathrm{~mm}$ thickness have been investigated. It was found that the main factor 
affecting the joint strength is the welding speed and the other two factors are slightly affecting the joint strength.

\subsection{Artificial Neural Networks}

Control of distortion and overall quality of welds were investigated by Casalino et al. [65] in order to select the GMAW process parameters that minimize thermal deformation and evaluate weld quality. They integrated the artificial intelligence techniques and FEM with the aid of experimental trials of bead-on-plate welds. The base metal was $1.6 \mathrm{~mm}$ thick low-carbon steel, a $0.9 \mathrm{~mm}$ diameter copper-coated wire was used as an electrode with a shielding gas consisting of a $75 \% \mathrm{Ar}-25 \% \mathrm{CO}_{2}$ mixture with flow rate of $10-15 \mathrm{ft}^{3} / \mathrm{h}$. ANN was used at first to link the process parameters to the geometry of the molten zone, which allowed the geometries throughout a range of process parameters to be calculated. Then FEM was applied to predict the residual stress value and distortion in the welded joint. Finally, fuzzy C-means clustering algorithm was applied to evaluate the quality joints. Mathematical models for GMAW were constructed. Experimentally butt welded joint were validated. It was concluded that the experimental result are in good agreement with the mathematical model.

Li-Ming et al. [66] have established a static model for $\mathrm{SiC}_{\mathrm{w}} / 6061 \mathrm{Al}$ metal matrix composites in diffusion welding using ANN. The relationship between welded joint strength and welding parameters, such as, welding temperature, welding pressure and welding time was presented. The effect of process parameters on the joint strength was demonstrated and optimal technical parameters were obtained. It was proven that the developed static model was in good agreement with the actual data.

Sterjovski et al. [67] introduced ANN modelling as an alternative technique to those currently in the literature to predict the hardness of HAZ, and hence, trying to control it to

minimize the risk of hydrogen assisted cold cracking in welding in-service pipelines by the hot tapping technique. The model developed included materials characteristics; chemical composition and hardness (as inputs), the peak temperature, holding time and cooling rate of the HAZ thermal cycle simulation were also used as key inputs in the model to predict the HAZ hardness. It was reported that the hardness of HAZ increases with increasing the following: carbon content, original hardness of pipe or fitting material and more rapid cooling. They compared the predictive capabilities of the models developed with other published works to the 
neural network model they developed. It was clear that the neural networks model produced a much lower error across a broader range of HAZ hardness values.

Lightfoot et al. [68] have used ANN to develop a model to study the FCAW process factors affecting the distortion of $6-8 \mathrm{~mm}$ thick D and DH grade steel plates. A sensitivity analysis was carried out, which highlighted a number of apparently key factors that influenced distortion. It was proven that the carbon content played a key role in the amount of distortion produced by the welding process. They found that an increase in the carbon content was beneficial in reducing thin plate distortion caused by welding. Also, they identified a number of distortion-related factors, such as carbon content, YS/TS ratio and rolling treatment. It was concluded that these factors can be controlled to reduce the distortion in 6-8 $\mathrm{mm}$ thick plates.

Sterjovski et al. [69] have applied the ANN models to predict the mechanical properties of steels in various applications, namely: impact strength of quenched and tempered pressure vessel steel exposed to multiple postweld heat treatment cycles, the hardness of the simulated HAZ in pipeline and lap fitting steel after in-service welding and the hot ductility and hot strength of various microalloyed steel over the temperature range for stand or slab straightening in continuous casting process. It was found that the three ANN models successfully predicted the mechanical properties. It was also shown that ANNs could successfully predict multiple mechanical properties and the result of the sensitivity analysis were in agreement with both findings of the experimental investigation and reported results in the literature. Furthermore, it was mentioned that the use of ANNs resulted in large economic benefits for organisations through minimizing the need for expensive experimental investigation and/or inspection of steels used in various applications.

Okuyucu et al. [70] developed a model using ANN for the analysis and simulation of the correlation between friction stir welding (FSW) parameters of aluminium plates and mechanical properties of the welded joint. The process parameters consist of weld speed and tool rotation speed verses the output mechanical properties of weld joint, namely: tensile strength, yield strength, elongation, hardness of WZ and hardness of HAZ. Good performance of the ANN model was achieved and the model can be used to calculate mechanical properties of the welded plates as a function of process parameters. Also, it was found that the correlation between the measured and predicted values of tensile strength, hardness of HAZ and hardness of weld metal were better than those of elongation and yield strength. 


\subsection{Taguchi Method}

Laser butt-welding of a thin plate of magnesium alloy using the Taguchi method has been optimized by Pan et al. [71]. They studied the effect of Nd-YAG laser welding parameters (shielding gas type, laser energy, conveying speed, laser focus, pulse frequency and pulse shape) on the ultimate tensile stress. Their result indicated that the pulse shape and energy of the laser contributed most to thin plate butt-welding. It was found that the optimal combination of welding parameters for laser welding were argon as a shielding gas, a $360 \mathrm{~W}$ laser energy, a workpiece speed of $25 \mathrm{~mm} / \mathrm{s}$, a focus distance of $0 \mathrm{~mm}$, a pulse frequency of $160 \mathrm{~Hz}$ and type III pulse shape. It was also found that the superior ultimate tension stress was $169 \mathrm{MPa}$ at an overlap of the welding zone of approximately $75 \%$.

Anawa et al. [72] have applied the Taguchi approach to optimize the laser welding process of dissimilar materials, namely: plain carbon steel and AISI316 with the same thickness of $1.5 \mathrm{~mm}$. The process parameters were laser power, welding speed and focus position against one response NTS. The experimental results indicated that the process could be optimized using the Taguchi method in order to obtain superior welded joints. Anawa et al. [73] have continued their investigation and studied the effect of the laser welding parameters mentioned above on the impact strength of the same joint at room temperature using the same optimizing technique. The results indicated that the laser power has the most significant effect on the impact strength. Also, it was mentioned that the optimal settings to obtain excellent impact strength were the highest laser power, a welding speed of $750 \mathrm{~mm} / \mathrm{min}$ and a focus position of $-0.5 \mathrm{~mm}$.

\subsection{Combination of two techniques}

ANN and Taguchi methods were used to predict the bead geometry parameters (front width, back width and depth of penetration) by Seshank et al. [74]. Aluminium plates were bead-onplate welded using pulsed current GTAW, the controlled parameters were: peak current, base to peak current ratio, \% time at peak current, frequency and welding speed. Taguchi's orthogonal array was used to set the welding conditions to be studied. Different ANNs were built to predict the responses. The results they achieved were found to be of good accuracy. An online relationship has been built to make the prediction of the depth of penetration possible if the top bead width is known. Moreover, it was found that a simple MLP with a single hidden layer with a 
Tanh transfer function and momentum learning is more effective than the networks that have two or three hidden layers.

Murugananth et al. [75] have coupled ANN model with optimization software, which utilize linear and nonlinear techniques to explore possible combination of carbon, manganese and nickel concentrations for a given set of welding parameters, to predict the weld metal composition that would maximise the toughness at $-60{ }^{\circ} \mathrm{C}$. The predicted weld metal composition was Fe-0.034C-0Mn-7.6Ni-0.65Si-0.038O-0.018N-0.013P-0.006S (wt.\%) and toughness of $87 \mathrm{~J} \pm 20 \mathrm{~J}$ at $60{ }^{\circ} \mathrm{C}$.

Factors that affect weld mechanical properties (oxygen, nitrogen, carbon, hydrogen and iron contents in the weld joint as well as the cooling rate) of commercially pure titanium have been investigated by Wei et al. [76]. ANNs techniques were used, to predict the ultimate tensile strength, yield strength, elongation, reduction of area, Vickers hardness and Rockwell B hardness. The input data was obtained from mechanical testing of single-pass autogenous welds. The ANN models were developed. An oxygen equivalent equation (OEE) was also used to predict the mechanical properties of $\mathrm{CP}$ titanium welds; a good agreement was found between both ANN and OEE. The obtained results indicated that both oxygen and nitrogen have the most significant effect on the strength while hydrogen has the least effect. Also, it was reported that cooling rate is more important than the carbon and iron content in the ultimate tensile strength model, and more important than oxygen and the iron content and equally important as the carbon content in the yield strength model.

\subsection{Other Techniques}

Canyurt [77] has extended the GA approach to the estimation of mechanical properties of the joints of brass material. He developed non-linear models to specify the effect of GTAW process parameters (gap between plates, torch angle, quantity of shielding gas, pulse frequencies and electrode tip angle) on the tensile strength of the welded joint. He examined the effect of the five welding parameters on the strength value using the genetic algorithm welding strength estimation model (GAWSEM). Also, he indicated that the changes in the gap between the joint parts from 0 to $0.5 \mathrm{~mm}$ leads to a 4.4 times decrease in the joint strength and changes in the torch angle from $60^{\circ}$ to $90^{\circ}$ leads to a 1.9 times increase in the joint strength. Furthermore, he reported 
that the optimum quantity of the shielding gas and the pulse frequencies were $16.51 / \mathrm{min}$ and 30 Hz.

\section{Comparison between the optimization techniques}

Derived from the above literature review some insight has been gained into the use of DoE, ANN, GA, Taguchi method and other techniques for modelling and optimizing different welding processes. It was noted that RSM performs better than other techniques, especially ANN and GA, when a large number of experiments are not affordable. The trend in the modelling using RSM has a low order nonlinear behaviour with a regular experimental domain and relatively small factors region, due to its limitation in building a model to fit the data over an irregular experimental region. Moreover, the main advantage of RSM is its ability to exhibit the factor contributions from the coefficients in the regression model. This ability is powerful in identifying the insignificant factors main effect, insignificant interactions or insignificant quadratic terms in the model and thereby can reduce the complexity of the problem. On the other hand, this technique required good definition of ranges for each factor to ensure that the response(s) under consideration is changing in a regular manner within this range. The most popular designs within RSM designs are the central composite design (CCD) and Box-Behnken design. In regard to ANNs, it noted that ANNs perform better than the other techniques, especially RSM when highly nonlinear behaviour is the case. Also, this technique can build an efficient model using a small number of experiments; however the technique accuracy would be better when a larger number of experiments are used to develop a model. On the other hand, the ANN model itself provides little information about the design factors and their contribution to the response if further analysis has not been done. The most popular ANNs are learning vector quantization neural networks, back-propagation and counter-propagation networks. In the case of GA, it is a powerful optimization tool especially in irregular experimental regions. The main characteristic of GAs over the other optimization techniques is that they operate simultaneously with a huge set of search space points to find the optimal welding condition instead of a single point. On the other hand, this technique required a good setting of its parameters and uses a large computational effort, and therefore a long run time. Also this technique does not develop mathematical models. The Taguchi method is also one of the powerful optimization techniques which characterize with improving the product quality and reliability at low cost. The optimization algorithm works by 
calculating signal-to-noise (SN) ratios for each combination and then the combination having a maximum SN ratio is defined as the optimal setting. However, Taguchi's analysis approach of SN may lead to non-optimal solutions, less flexibility and the conduction of needless experiments. Table 1 presents a comparison between the above mentioned common modelling/optimizing algorithms methods based on this literature review.

Table 1: Comparison between the common modelling/optimizing techniques

\begin{tabular}{|c|c|c|c|c|c|}
\hline Comparison & ANNs & GA & RSM & Taguchi & $\begin{array}{l}\text { Factorial } \\
\text { Designs }\end{array}$ \\
\hline Computational time & Long & Very long & Short & Medium & Short \\
\hline Experimental domain & $\begin{array}{l}\text { Regular or } \\
\text { irregular }\end{array}$ & $\begin{array}{l}\text { Regular } \\
\text { or } \\
\text { irregular }\end{array}$ & $\begin{array}{l}\text { Regular } \\
\text { only }\end{array}$ & $\begin{array}{l}\text { Regular } \\
\text { or } \\
\text { irregular }\end{array}$ & Regular only \\
\hline Model developing & Yes* & No & Yes & No & Yes† \\
\hline Optimization & $\begin{array}{c}\text { Through } \\
\text { model }\end{array}$ & Straight & $\begin{array}{c}\text { Through } \\
\text { model }\end{array}$ & Straight & $\begin{array}{l}\text { Through } \\
\text { model }\end{array}$ \\
\hline Understanding & Moderate & Difficult & Easy & Normal & Easy \\
\hline Availability in software & Available & Available & Available & Available & Available \\
\hline Optimization Accuracy level & High & High & Very high & Normal & Very high \\
\hline Application & Frequently & Rarely & Frequently & Rarely & Frequently \\
\hline
\end{tabular}

*) No factors interaction effects. †) No factors quadratic effects.

\section{Conclusion}

The optimization methods covered in this survey are appropriate for modelling, control and optimizing the different welding process. The survey reveals the high level of interest in the adaptation of RSM and ANNs to predict response(s) and optimize the welding process. Generally, there is a lack of comparative study regarding the performance of the optimization methods, in other words for a given optimization problem which method would suit better. Combining two optimization techniques, such as GA and RSM, would reveal good results for finding out the optimal welding conditions. Future work should focus on the application of these modelling and optimization techniques to find out the optimal welding combinations for a certain welding process at which the process could be considered safe, environment friendly and economical. 


\section{References}

[1] D. Radaj, Heat effects of welding- temperature field, residual stress, Distortion, Springer-Verlag, 1992.

[2] L. P. Connor, Welding Handbook-welding processes, Vol. 2, 8th Ed, American welding Society, 1991.

[3] J. Raveendra and R. S. Parmar, Mathematical models to predict weld bead geometry for flux cored arc welding, J. of Metal construction, Vol. 19, n. 2, January 1987, pp. 31R-35R

[4] V. K. Gupta and R. S. Parmar, Fractional factorial technique to predict dimensions of the weld bead in automatic submerged arc welding, IE(I) Journal-MC, Vol. 70, Nov. 1989, pp.67-75.

[5] N. Murugan, R. S. Parmar and S. K. Sud, Effect of submerged arc welding process variables on dilution and bead geometry in single wire surfacing, J. of Material Processing Technology, Vol. 37, 1993, pp. 767-780.

[6] N. Murugan and R. S. Parmar, effects of MIG process parameters on the geometry of the bead in the automatic surfacing of stainless steel, J. of Materials Processing Technology, Vol. 41, 1994, pp. 381-398.

[7] L. J. Yang, M. J. Bibby and R. S. Chandel, Linear regression equations for modelling the submerged-arc welding process, J. of Materials Processing Technology, Vol. 39, 1993, pp. 33-42.

[8] C. M. D. Starling, P. V. Marques and P. J. Modenesi, Statistical modelling of narrow-gap GTA welding with magnetic arc oscillation, J. of Material Processing Technology, Vol. 51, 1995, pp. 37-49.

[9] I. S. Kim, J. S. Son, I. G. Kim and O. S. Kim, A study on relationship between process variable and bead penetration for robotic CO2 arc welding, J. of Materials Processing Tech., Vol. 136, 2003, pp. 139-145.

[10] I. S. Kim, K. J. Son, Y. S. Yang and P. K. D. V. Yaragada, Sensitivity analysis for process parameters in GMA welding processes using a factorial design method, Inter. J. of Machine Tools \& manufacture, Vol. 43, 2003, pp. 763-769.

[11] N. Murugan and R. S. Parmar, Effect of welding conditions on microstructure and properties of tupe 316L stainless steel submerged arc welding cladding, Welding Journal, AWS, Vol. 76, n. 5, May 1997, pp. 210-s220-s.

[12] V. Gunaraj and N. Murugan, Application of response surface methodology for predicting weld bead quality in submerged arc welding of pipes, J. of Materials Processing Tech., Vol. 88, 1999, pp. 266-275.

[13] V. Gunaraj and N. Murugan, Prediction and comparison of the area of the heat-affected zone for the bead-onplates and bead-on-joint in submerged arc welding of pipes, J. of Materials Processing Tech., Vol. 95, 1999, pp. 246-261.

[14] E. Koleva, Statistical modelling and computer programs for optimisation of the electron beam welding of stainless steel, J. Vacuum, Vol. 62, 2001, pp. 151-157.

[15] V. Gunarai and N. Murugan, Prediction and optimization of weld bead volume for the submerged arc processpart 1, Welding journal, AWS, October 2000, 286-s - 294-s.

[16] V. Gunarai and N. Murugan, Prediction and optimization of weld bead volume for the submerged arc processpart 2, welding journal, AWS, November 2000, 331-s - 338-s.

[17] Gunaraj and Murugan, Prediction of heat-affected zone characteristics in submerged arc welding of structural steel pipes, welding journal, AWS, January 2002, 94-s - 98-s.

[18] K .Manonmani, N. Murugan and G. Buvanasekaran, Effect of process parameters on the weld bead geometry of laser beam welded stainless steel sheets, Inter. J. for the Joining of Materials, Vol. 17, n. 4, 2005, pp.103-109.

[19] Gunaraj and Murugan, Prediction and control of weld bead geometry and shape relationships in submerged arc welding of pipes, J. of Materials Processing Tech., Vol. 168, 2005, 478-487.

[20] E. Koleva, Electro beam weld parameters and thermal efficiency improvement, Vacuum J., Vol. 77, 2005, pp. 413-421

[21] K. Y. Benyounis, A. G. Olabi and M. S. J. Hashmi, Effect of laser welding parameters on the heat input and weld-bead profile, J. of Materials Processing Tech., Vol. 164-165, 2005, 978-985.

[22] K. Y. Benyounis, A. G. Olabi and M. S. J. Hashmi, Optimizing the laser-welded butt joint of medium carbon steel using RSM, J. of Materials Processing Tech. Vol. 164-165, 2005, pp. 986-989.

[23] E. Koleva and I. Vuchkov, Model-based approach for quality improvement of electro beam welding applications in mass production, J. Vacuum, Vol. 77, 2005, pp. 423-428.

[24] T. Kannan and N. Murugan, Effect of flux cored arc welding process parameters on duplex stainless steel clad quality, J. of Material Processing Technology, Vol. 176, 2006, pp. 230-239.

[25] K. Andersen, G. Cook, G. Karsai nad K. Ramaswmy, Artificial neural network applied to arc welding process modelling and control, IEEE Transactions on Industry Applications, Vol. 26, n. 5, Sep./Oct. 1990, pp. 824830 . 
[26] G. Cook, R. J. Barnett, K. Andersen and A. M. Strauss, Weld modelling and control using artificial neural networks, IEEE Transactions on Industry Applications, Vol. 31, n. 6, Nov/Dec. 1995, pp. 1484-1491.

[27] J. M. Vitek, Y. S. Iskander, E. M. Oblow et al., Neural network modeling of pulsed-laser weld pool shapes in aluminum alloy welds, proceedings of 5th Inter. Conf. on Trends in Welding Research, Pine Mountain, GA, June 1-5.1998, ASM Inter., pp.442-448.

[28] S.C. Juang, Y. S. Tarng and H. R. Lii, A comparison between the back-propagation and counter-propagation networks in the modelling of the TIG welding process, J. of Material Processing Technology, Vol. 75, 1998, pp. 54-62.

[29] B. Chan, J. Pacey and M. Bibby, Modelling gas metal arc weld geometry using artificial neural network technology, J. of Canadian Metallurgical Quarterly, Vol. 38, n. 1, 1999, pp. 43-51.

[30] J. Y. Jeng, T. Mau and S. Leu, Prediction of laser butt joint welding parameters using back propagation and learning vector quantization networks, J. of Materials Processing Technology, Vol. 99, 2000, pp. 207-218.

[31] D.S. Nagesh and G. L. Datta, Prediction of weld bead geometry and penetration in shielded metal-arc welding using artificial neural networks, J. of Materials Processing Technology, Vol. 123, 2002, pp.303-312.

[32] G. E. Ridings, R. C. Thomson and G. Thewlis, Prediction of multiwire submerged arc weld bead shape using neural network modelling, J. of Science and Technology of welding and joining, Vol. 7, n. 5, 2002, pp. 265279.

[33] K. H. Christensen, T. SØrensen and J. K. Kristensen, Gas metal arc welding of butt joint with varying gap width on neural networks, J. of Science and Technology of welding and joining, Vol. 10, n.1, 2005, pp. 32-43.

[34] S. C. Juang and Y. S. Tarng, Process parameters selection for optimizing the weld pool geometry in the tungsten inert gas welding of stainless steel, J. of Materials Processing Technology, Vol. 122, 2002, 33-37.

[35] H. K. Lee, H. S. Han, K. J. Son and S. B. Hong, Optimization of Nd-YAG laser welding parameters for sealing small titanium tube ends, J. of Materials Science and Engineering, Vol. A415, 2006, pp. 149-155.

[36] J. Lee and K. Um, A comparison in a back-bead prediction of gas metal arc welding using multiple regression analysis and artificial neural network, J. of Optics and Lasers in Engineering, Vol. 34, 2000, pp. 149-158.

[37] H. Park and S. Rhee, Estimation od weld bead size in Co2 laser welding by using multiple regression and neural network, J. of Laser Application, Vol. 11. n. 3, 1999, pp.143-150.

[38] I. S. Kim, J. S. Son, C. E. Park, C. W. Lee and Y. K. D. V. Prasad, A study on prediction of bead height in robotic arc welding using a neural network, J. of Materials Processing Technology, Vol. 130-131, 2002, pp. 229-234.

[39] G. Casalion, and F. M. C. Minutolo, A model for evaluation of laser welding efficiency and quality using an artificial neural network and fuzzy logic, J of Engineering Manufacture, Vol. 218, part B, 2004, pp. 1-6.

[40] D. Kim, S. Rhee, and H. Park, Modelling and optimization of a GMA welding process by genetic algorithm and response surface methodology, Int. J. of Prod. Res., Vol. 40, n. 7, 2002, pp. 1699-1711.

[41] D. S. Correia, C. V. Goncalves, S. S. da Cunha and V. A. Ferraresi, Comparison between genetic algorithms and response surface methodology in GMAW optimization, J. of Materials Processing Tech., Vol. 160, 2005, pp. 70-76.

[42] D. Kim, M. Kang and S. Rhee, Determination of optimal welding conditions with a controlled random search procedure, Welding journal, AWS, August 2005, 125-s - 130-s.

[43] Y. S. Tarng, H. L. Tsai and S. S. Yeh, Modeling, Optimization and classification of weld quality in tungsten inert gas welding, Inter. J. of Machine tools \& Manufacture, Vol. 39, 1999, pp. 1427-1438.

[44] P. Harris and B. L. Smith, Factorial techniques for weld quality prediction, J. of Metal Construction, November 1983, pp. 661-666.

[45] K. G. K. Murti and S. Sundaresan, Parameter optimization in friction welded dissimilar materials, J. of Metal Construction, Vol. 15, n. 6, June 1983, pp. 331-335.

[46] S. K. Arya and R. S. Parmar, Mathematical models for predicting angular distortion in CO2-shielded flux cored arc welding, in the proceedings of Inter. Conf. on joining of Metals (JOM-3), Helsingor, Denmark, 1986, pp. 240-245.

[47] Y. Zhou, Z. Li, L. Hu, A. Fuji and T. H. North, Mechanical properties of particulate MMC/AISI 304 friction joints, J. of ISIJ Inter., Vol. 35, n. 10, 1995, pp. 1315-1321.

[48] V. Balasubramanian and B. Guha, Assessment of some factors affecting fatigue endurance of welded cruciform joints using statistical techniques, Inter. J. of Fatigue, Vol. 21, 1999, pp. 873-877.

[49] V. Balasubramanian and B. Guha, Fatigue life prediction of load carrying cruciform joints of pressure vessel steel by statistical tools, J. of Materials and Design, Vol. 25, 2004, pp. 615-623. 
[50] R. Koganti, C. Karas, A. Joaquin, D. Henderson, M. Zaluzec and A. Caliskan. Metal inert gas (MIG) welding process optimization for joining aluminium sheet material using OTC/DAIHEN equipment, Proceedings of IMECE'03, ASME Inter. Mech. Eng. Congress, Washington, D. C. , Nov. 15-21, 2003, pp.409-425.

[51] K. Sampath, Constrains-based modelling Enables successful development of welding electrode specification for critical navy application, Welding journal, AWS, Aug. 2005, pp. 131-s -138-s.

[52] T. Pine, M. M. Lee, and T. B. Jones, Factors affecting torsional properties of box sections, J. of Ironmarking and Steelmarking, Vol. 25, n. 3, 1998, pp. 205- 209.

[53] K. K. Wang and G. Rasmussen, Optimization of inertia welding process by response surface methodology, J. of Engineering for Industry, Vol. 94, n. 4, 1972, pp. 999-1006.

[54] H. Yamaguchi, K. Ogawa and K. Sakaguchi, Optimization of friction welding condition of 5056 aluminium alloy, J. of Japan Institute of Light metal, Vol. 41, n. 10, 1991, pp. 716-720.

[55] O. Koichi, Y. Hiroshi, K. Seiichi and S. Kazuhiko, Optimization of friction welding condition for S4 5C carbon steel using a statistical technique, J. of Japan Welding Society, Vol. 24, n. 2, 1993, pp. 47-53.

[56] K. Y. Benyounis, A. H. Bettamer, A. G. Olabi and M. S. J. Hashmi, Prediction the impact strength of spiralwelded pipe joints in Submerged arc welding of low carbon steel, Proceedings of IMC21, Limerick 1-3-Sep. 2004, pp. 200-210.

[57] E. S. Ege, O. T. Inal and C. A. Zimmerly, Response surface study on production of explosive-welded aluminium-titanium laminates, J. of Materilas Science, Vol. 33, 1998, pp. 5327-5338.

[58] T. T. Allen, R. W. Richardson, D. P. Tagliabue and G. P. Maul, Statistical process design for robotic GMA welding of sheet metal, Welding Journal, AWS, May 2002, pp. 69-s - 77-s.

[59] K. Raghukandan, Analysis of the explosive cladding of Cu-low carbon steel plates, J. of Materials Processing Technology, Vol. 139, 2003, pp. 573-577.

[60] V. V. Murugan and V. Gunaraj, Effects of process parameters on angular distortion of gas metal arc welded structural steel plates, Welding Journal, AWS, Nov. 2005, pp. 165-s - 171-s.

[61] K. Y. Benyounis, A. G. Olabi and M. S. J. Hashmi, Estimation of mechanical properties of laser welded joints using RSM, Proceedings of IMC22, Institute of Technology Tallaght, Dublin- Ireland, 31 Aug.- 2 Sep. 2005, pp. 565-571.

[62] K. Y. Benyounis, A. G. Olabi and M. S. J. Hashmi, Residual stresses prediction for CO2 laser butt-welding of 304- stainless steel, Applied Mechanics and materials, Trans Tech publications, Vols. 3-4 , pp. 125-130..

[63] A. G. Olabi, K. Y. Benyounis, M. S. J. Hashmi, Application of RSM in describing the residual stress distribution in CO2 laser welding of AISI304, Strain Journal, Vol. 43, No. 1, 2007, pp. 37-46.

[64] K. Y. Benyounis, A. G. Olabi and M. S. J. Hashmi, Effect of laser welding parameters on the tensile-shear strength of AISI304 sheet, Published in AMPT2006 proceedings, July 30- Aug. 3, 2006, Ohio university, Athens, Ohio, USA.

[65] G. Casalino, S. J. Hu and W. Hou, Deformation prediction and quality evaluation of the gas metal arc welding butt weld, J. of Engineering Manufacture, Vol. 217 part B, pp. 1-8.

[66] L. Li-ming, Z. Mei-li, N. Ji-tai and Z. Zhong-dian, Predicting effects of diffusion welding parameters on welded joint properties by artificial neural network, J. of Yrans. Nonferrous Metal Society China, Vol. 11, n. 4, Aug. 2001, pp. 475-478.

[67] Z. Sterjovski, D. Nolan, D. Dunne and J. Norrish, Predicting the HAZ hardness of pipeline and tap fitting steels with artificial neural networks, in Proceedings of the 4th Inter. Conf. on pipeline technology, University of Wollongong, NEW, Australia, 2004, pp. 1233-1245.

[68] M. P. Lightfoot, G. J. Bruce, N. A. McPherson and K. Woods, The application of artificial neural networks to weld-induced deformation in ship plate, Welding J., AWS and WRC, February 2005, pp. 23-s - 26-s.

[69] Z. Sterjovski, D. Nolan, K. R. Carpenter, D. P. Dune and J. Norrish, Artificial neural network for modelling the mechanical properties of steels in various applications, J. of Materials Processing Technology, Vol. 170, No. 3, 2005, pp. 336-544.

[70] H. Okuyucu, A. Kurt and E. Arcaklioglu, Artificial neural network application to the friction stir welding of aluminium plates, J. of Materials \& Design, Vol. 29, 2007, pp. 78-84.

[71] L. K. Pan, C. C. Wang, Y. C. Hsiso and K. C. Ho, Optimization of Nd-YAG laser welding onto magnesium alloy via Taguchi analysis, J. of Optics \& Laser Technology, Vol. 37, 2004, pp. 33-42.

[72] E. M. Anawa, A. G. Olabi and M. S. J. Hashmi, Optimization of ferritic/Austenitic laser welded components, presented at AMPT2006 Inter. Conf. July 30 - Aug. 3, 2006, Las Vegas, Nevada, USA, 2006.

[73] E. M. Anawa and A. G. Olabi, Effect of laser welding conditions on toughness of dissimilar welded components, J. of Applied Mechanics and Materials, Vol. 5-6, 2006, 375-380. 
[74] K. Seshank, S. R. K. Rao, Y. Singh and K. P. Rao, Prediction of bead geometry in pulsed current gas tungsten arc welding of aluminium using artificial neural networks, Proceedings of Inter. Conf. on Information and Knowledge Engineering, IKE 03, June 23 - 26, 2003, Las Vegas, Nevada, USA, pp. 149- 153.

[75] M. Murugananth, S. S. Babu and S. A. David, Optimization of shielded metal arc weld metal composition for charpy toughness, Welding Journal, AWS, Oct. 2004, pp. 267-s-276-s.

[76] Y. Wei, H. K. D. Bhadeshia and T. Sourmail, Mechanical property prediction of commercially pure titanium welds with artificial neural network, J. of Material Science Technology, Vol. 21, n. 3, 2005, pp. 403-407.

[77] O. E. Canyurt, Estimation of welded joint strength using genetic algorithm approach, Inter. J. of Mechanical Sciences, Vol. 47, 2005, pp. 1249-1261. 